\title{
Preliminary evaluation of indoor thermal comfort in Malaysia heritage mosque
}

\author{
$W F M$ Yusoff $^{1,2, *}$, and $N H$ Ja'afar ${ }^{1,2}$ \\ ${ }^{1}$ Centre for Innovative Architecture and Built Environment, Faculty of Engineering and Built \\ Environment, Universiti Kebangsaan Malaysia, Malaysia \\ ${ }^{2}$ Secretariat for National Identity Architecture, Faculty of Engineering and Built Environment, \\ Universiti Kebangsaan Malaysia, Malaysia
}

\begin{abstract}
Malaysia heritage buildings are the country's architectural gems. Among them is the religious building such as mosque. The Malaysia heritage mosque is normally built in response to the local culture and environment. Unlike most of Malaysia modern mosques where air conditioning is opted as ventilation mode, the heritage mosques achieve indoor thermal comfort via the passive architectural design. Due to that, this study was executed with the purpose of investigating the indoor thermal comfort of a Malaysia heritage mosque located at traditional street in Melaka, namely Masjid Tanah. The methodology used in the study was field measurement, in which the parameters measured were the indoor and outdoor air temperatures. The field measurement was conducted for two days in the end of March and early of April 2018, from 9 am to $4 \mathrm{pm}$. The indoor predicted comfort temperature was derived using the adaptive model. The findings indicated that the measured indoor air temperatures were lower than the indoor predicted comfort temperatures at most of the time. Therefore, it shows that the passive architectural design adopted by the Malaysia heritage mosque, which is Masjid Tanah, is able to provide indoor thermal comfort to the users.
\end{abstract}

\section{Introduction}

The Oxford Dictionary defines heritage as anything that is inherited, while for a heritage building, it is referred as a nation's historic building that is worth to be preserved [1]. However, according to Wilkinson and Remoy [2], there is no explicit definition of heritage building, but the criteria represented by it consist of cultural, historical, inherent and symbolic values, as well as having relationship with the location. Meanwhile, in the Malaysia National Heritage Act 2005 [3], the word heritage is defined as a generic national heritage such as sites, objects or cultural heritage, whether it is registered or not in the National Heritage List. Therefore, from those definitions, heritage building can be summarized as any building that has heritage value to the people, place or nation. Traditional buildings are not necessarily indicated as heritage buildings as they are normally buildings of custom that represent the people, place and culture. Heritage

*Corresponding author: wardahyusoff@ukm.edu.my 
buildings encompass many functions such as transportation buildings, factories, religious buildings, offices, apartments and many more [4].

Heritage buildings are normally situated at the traditional streets. This is because they normally possess strong relationship with the locations and context. Even, some of the buildings are the main factor that contribute to the growth of the population and township where they are located. During their early period of existence, they may become the centre for people's activities, such as the religious and communal buildings. These functions may remain till nowadays or may also change according to the needs and suitability. Traditional streets are the streets that are located in an old town that has historical value. Other characteristics that made a street becomes traditional street are the surrounding buildings and activities which have historical values, as well as the surrounding topography such as the presence of river, which once played significant role in the development of the area [5]. In Malaysia, the traditional streets usually characterized by the presence of old shophouses that encompass public walkway, which is also called five-foot walkway. The activities along the street are normally dominated by informal trading or retailing, which sometimes also occur at the five-foot walkway [6].

The studies of heritage buildings have been conducted since long time ago as people value the existence of such buildings in documenting the history of one civilization. Among the scope of studies are the building functions [7;4], the energy performance [8], the building structures [9], the indoor environment [10] and many more. A comfort indoor environment of a heritage building is of paramount importance as it affects the people's activities inside the building. Indoor thermal comfort is one of the indoor environmental parameters as it relates to the thermal condition of the indoor spaces, such as the hot and cold conditions.

People are stated to be in thermal comfort conditions when they are satisfied with the thermal environment. Though satisfaction is very subjective and vary among different people, efforts of identifying thermal comfort conditions are still ongoing till nowadays, using various thermal comfort models. During the initial study of thermal comfort, people used the PMV model developed by Fanger. This model was initially developed for temperate climate by conducting experiment in a controlled environment. With that controlled environment, this model is stated to be suitable for a steady-state environment only. It involves six parameters namely air temperature, relative humidity, mean radiant temperature, air movement, metabolic rate and clothing insulation [11]. Through time, people realize that humans have the ability to adapt themselves to the changes in the environment. With that awareness, another model was developed for thermal comfort study which is adaptive model.

The adaptive model was initially developed by Nicol and Humphreys with the realization that in actual condition, people adapt to larger range of temperature compared to the range predicted by PMV model. The ability to adapt depends on many factors such as climatic conditions, cultural background, as well as physiological and psychological aspects. In the adaptive model, the outdoor air temperature is indicated to have significant role in influencing the indoor comfort temperature [12]. Hence, in the adaptive model, people with different backgrounds and climatic conditions may have different ranges of thermal comfort.

The ability of people to adapt to the surrounding climate is proven via previous studies of thermal comfort such as by Caetano et al. [13] and Yusoff [14]. The findings of these studies indicated that people in hot and humid climate tend to accept higher air temperature as their comfort temperature. Caetano et al. [13] investigated office buildings in Brazil, where though they were air-conditioned, the workers still had freedom to control their indoor environment by opening the windows. The study adopted PMV model, in which based on the model, the derived indoor comfort temperatures were between $22.5^{\circ} \mathrm{C}$ to 25.5 ${ }^{\circ} \mathrm{C}$. Nevertheless, the study concluded that people in hot and humid climate able to tolerate 
and adapt to higher air temperature. This is due to the interesting findings where there were respondents who felt slightly cold or neutral at the indoor air temperature of above $26{ }^{\circ} \mathrm{C}$. Meanwhile, in the study by Yusoff [14] which was executed in Malaysia, the number of respondents who felt neutral or slightly warm at $33{ }^{\circ} \mathrm{C}$ were equal, in which these numbers were the majority. In addition, majority of the respondents were also satisfied with such indoor air temperature condition.

As the PMV model was developed under a controlled environment, it is more appropriate for buildings that are air-conditioned [13]. On contrary, the adaptive model was stated to be more suitable for the naturally ventilated building which has a continuously changing environment $[13 ; 15]$. Therefore, the selection of appropriate thermal comfort model depends on the condition of the investigated indoor environment. In this study, the adaptive model was employed instead of the PMV model as the investigated heritage mosque, which was Masjid Tanah, was designed to utilize natural ventilation.

In term of the equation, the PMV model is much more complex in comparison to the adaptive model. The adaptive model equation just requires the outdoor air temperature value only in deriving the neutral temperature or indoor predicted comfort temperature [11]. Among the adaptive model equation that can be utilized is the one that was developed by Humphreys et al. [16]:

$$
\operatorname{Tn}=13.8+0.53( \pm 0.02) \text { To }
$$

where $\mathrm{Tn}$ is the neutral temperature or indoor predicted comfort temperature, and To is the average outdoor air temperature. All the temperatures are in Degree Celsius unit. In this study, the adaptive model equation developed by Humphreys et al. [16] was used to search the indoor predicted comfort temperature. This temperature is essential in having initial idea on the appropriate indoor temperature that provides comfort to the users.

For a heritage building, it is necessary to evaluate its present environmental performance. This is because the environmental performance of a building consists of parameters that respond directly to the current situation. The changes in the climatic and surrounding elements will influence the environmental performance. For example, the surrounding development such as urbanization will alter the surrounding context where the building is located, hence affects the climatic elements such as the wind and air temperature profiles of the area. Basically the environmental performance and energy usage of a building are not associated with the time it is constructed, but more to the architectural and technological solutions that are implemented in it [8]. Therefore, this study intends to examine the environmental performance of a heritage building by focusing on the indoor thermal comfort. The selected heritage building in this study is a mosque due to its significant function in a community. The findings from this study provide initial idea whether the architectural and technological solutions adopted by the heritage mosque have good respond to the local climate and environment throughout the ages.

\section{The description of Masjid Tanah}

Masjid Tanah was selected for this study due to its uniqueness in term of its history, location, simple layout plan, construction materials and three-tier pitched roof. Masjid Tanah, located in the district of Alor Gajah, Melaka, is one of the traditional mosques in Melaka that has been gazetted as Melaka heritage building by Melaka State Museum Corporation. It was originally built in 1800 s by a Muslim scholar from Gujerat. However, in 1951 it had undergone some renovation to fulfil the needs and convenience of the users.

Its strategic location which is at the junction that connects the traditional streets, as well as besides a river has made this mosque one of a significant landmark in that area (figure 1). Moreover, the town where it is situated is also named after the mosque. Therefore, when 
people refer to Masjid Tanah, it can be either the town, which name is also Masjid Tanah, or the mosque itself. The mosque is also surrounded by old shophouses that accommodate heritage businesses such as jewellery shops, restaurants, traditional attire shops and many more. The streets at the area are called traditional streets as they are located in an old town that has historical value.

The word 'tanah' in Malay language means soil. The mosque had been named as Masjid Tanah due to its walls that were constructed using mixture of egg white, sand and laterite. Hence, the overall thickness of the wall is $250 \mathrm{~mm}$, which is thicker than the normal brick construction nowadays. With all the uniqueness mentioned above, it is undeniable that Masjid Tanah is a valuable heritage to the country.
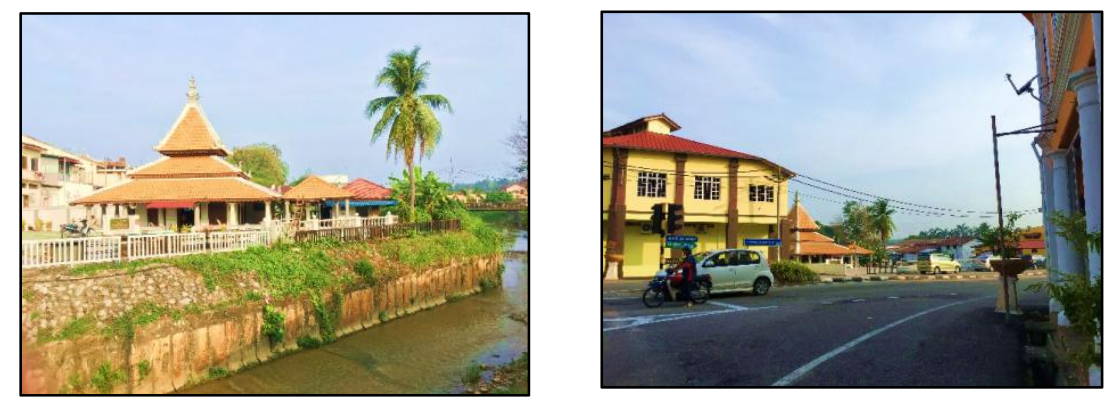

Fig. 1. The location of Masjid Tanah.

Masjid Tanah is considered a mosque with a simple layout plan compared to the modern Malaysian mosque layout nowadays. It has a praying hall area with the size of approximately $61 \mathrm{~m}^{2}$, and surrounded by veranda (figures $2 \mathrm{a}$ ). At the end of the praying hall is a 'mihrab', which is a small area that is usually designated for 'imam' or leader of the prayers. The roof of the mosque is also unique as it is composed of three-tier pitched roof, made of clay roof tiles (figure 2b). This configuration of roof, which is the three-tier pitched roof, is very synonym with the traditional mosques in Melaka.

Among the passive design characteristics adopted by the mosque are the three-tier pitched roof that provides appropriate height between floor and roof level for good natural ventilation, as well as wide roof overhang, which is about $1 \mathrm{~m}$ length, that protects the indoor area from heavy rain and direct solar radiation. Moreover, the veranda all around the mosque also functions as buffer zone that prohibits the direct penetration of solar radiation into the praying hall (figure 2a). In addition, the presence of openings at all walls also allow cross ventilation to occur.

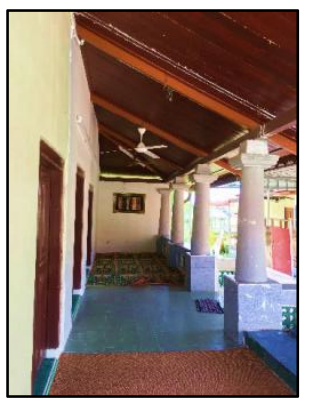

(a)

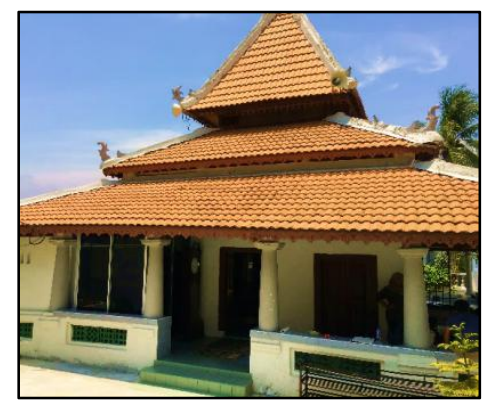

(b)

Fig. 2. The veranda (a), and the three-tier pitched roof (b) of Masjid Tanah.

\section{Research methodology}


The research methodology employed in this study was field measurement, in which the parameters measured were outdoor and indoor air temperatures. Since the study was a preliminary evaluation, hence the measurement was executed for short duration only which was two days. The measurement was conducted on 31st March and 1st April 2018, from 9 am to $4 \mathrm{pm}$. The measuring tools used for the measurement were two sets of multiparameter ventilation meters namely TSI Velocicalc 9565 series (figure 3). The measuring tools were able to measure and record various parameters such as air temperature, relative humidity, air pressure and air velocity. In this study, the parameter measured was air temperature. The accuracy for air temperature measurement was $\pm 0.3^{\circ} \mathrm{C}$.

Prior to actual measurement, the measuring tools were calibrated by placing them in parallel, and at the same height, which was about $1 \mathrm{~m}$ above the floor level. The process of calibration was executed for 5 hours. The results of calibration showed that the differences in the air temperature readings between the two measuring tools were less than $0.5 \%$.

During the actual measurement, the measuring tools were placed at the indoor and outdoor area as shown in figure 4. The locations were selected with the consideration of the safety of the measuring tools, as well as the reliability of the measured data. The measuring tools were located at $1.2 \mathrm{~m}$ height from the floor level, which was within the normal height of a human. The air temperature data was recorded every five minutes interval.

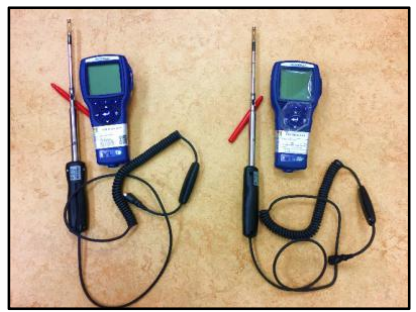

Fig. 3. The two sets of multiparameter ventilation meters namely TSI Velocicalc 9565 series.

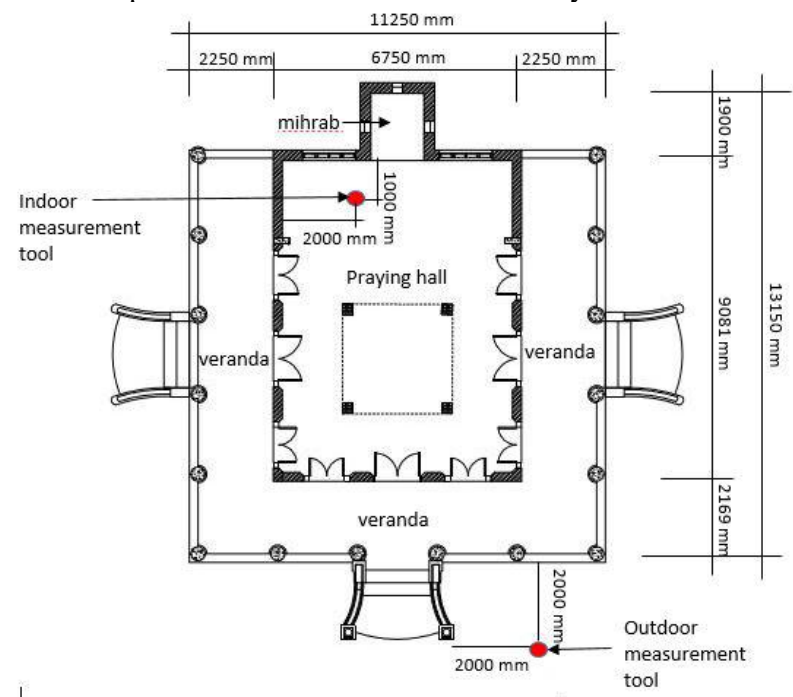

Fig. 4. The locations of the indoor and outdoor measuring tools.

\section{Results and discussion}

The average outdoor and indoor air temperatures for two days measurement were presented in table 1 . The data tabulated in table 1 shows that the air temperature differences between 
the outdoor (To) and indoor (Ta) were less than $7{ }^{\circ} \mathrm{C}$ at all time. The highest air temperature difference was $6.8^{\circ} \mathrm{C}$, which was at $11 \mathrm{am}$, whilst the lowest was at $4 \mathrm{pm}$, which was $0.8{ }^{\circ} \mathrm{C}$. Hence, the data indicated that the heat accumulated inside the building through time, where in the late afternoon, the indoor air temperature was almost similar to the outdoor air temperature. Nevertheless, the indoor air temperature was still lower than the outdoor air temperature at all time.

Table 1. The air temperature differences between the outdoor (To) and indoor (Ta).

\begin{tabular}{|l|c|c|c|}
\hline & $\begin{array}{c}\text { Outdoor air temperature, } \\
\text { To }(\operatorname{degC})\end{array}$ & $\begin{array}{c}\text { Indoor air temperature, Ta } \\
(\text { degC) }\end{array}$ & $\begin{array}{c}\text { Differences (To - Ta) } \\
(\text { degC) }\end{array}$ \\
\hline $9 \mathrm{am}$ & 35.9 & 29.5 & 6.4 \\
\hline $10 \mathrm{am}$ & 36.1 & 30.2 & 5.8 \\
\hline $11 \mathrm{am}$ & 37.8 & 30.9 & 6.8 \\
\hline $12 \mathrm{pm}$ & 37.3 & 31.6 & 5.7 \\
\hline $1 \mathrm{pm}$ & 35.8 & 31.9 & 3.9 \\
\hline $2 \mathrm{pm}$ & 34.9 & 32.1 & 2.8 \\
\hline $3 \mathrm{pm}$ & 33.8 & 32.2 & 1.6 \\
\hline $4 \mathrm{pm}$ & 32.9 & 32.1 & 0.8 \\
\hline
\end{tabular}

The results depicted in figure 5 were derived using the adaptive model equation developed by Humphreys et al. [16]. The results indicated that during the morning hours and until $1 \mathrm{pm}$, the measured indoor air temperatures (Ta) were lower than the indoor predicted comfort temperatures (Tn). However, starting from $2 \mathrm{pm}$ and above, the results were vice versa.

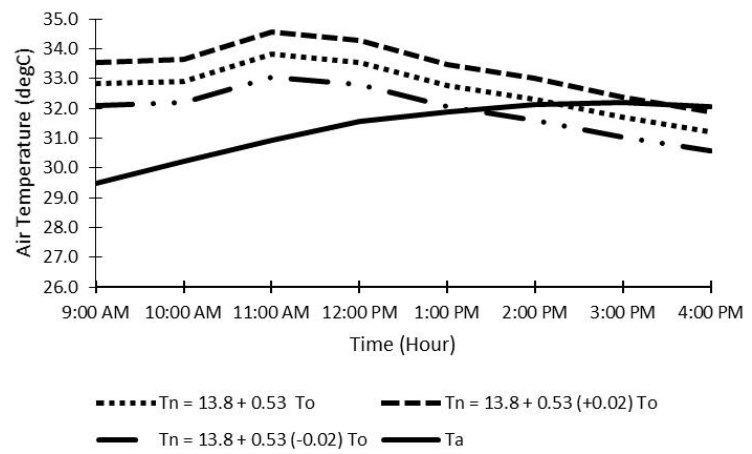

Fig. 5. The comparison between the indoor predicted comfort temperature (Tn) and measured indoor air temperature (Ta).

Therefore, the results depicted in table 1 and figure 5 show that thermal comfort was able to be achieved for the indoor environment of Masjid Tanah, especially during the morning hours. Though the outdoor air temperatures demonstrated high values during the morning hours, which were more than $35^{\circ} \mathrm{C}$, the indoor environment of Masjid Tanah was still comfortable for the users. The highest measured indoor air temperature recorded during the study was at $3 \mathrm{pm}$, which was $32.2{ }^{\circ} \mathrm{C}$. This value is still lower than the accepted comfort temperature by the respondents in the study by Yusoff [14], which was $33^{\circ} \mathrm{C}$.

The comfortable indoor environment of Masjid Tanah is due to the presence of veranda all around that prevents direct penetration of solar radiation into the praying hall. However, the accumulation of heat through time had made the indoor environment slightly warmer in the afternoon, though there was reduction of outdoor air temperature compared to the morning hours.

\section{Conclusion}


The study shows that heritage building is among the best example to learn about local architectural characteristics that have good respond to the local climate and environment. The passive design characteristics of Masjid Tanah that respond to the local tropical climate of Malaysia have enabled the indoor environment of the praying hall to be in thermal comfort condition most the time. Its simple layout plan with no indoor partition, as well as the presence of many openings also allow good cross ventilation to occur. The existence of veranda also prohibits the penetration of direct solar radiation into the praying hall. With the evolution of mosque design nowadays, it is important to note that the shading of the facades and indoor spaces from direct solar radiation, as well as effective cross ventilation must be highly considered in achieving indoor thermal comfort in hot and humid climate. The globalization and modernization have made these two aspects sometimes ignored in the building design nowadays.

It is also important to note that this study is just a preliminary evaluation of thermal comfort condition in a heritage mosque via field measurement and adaptive model equation. Regarding to the positive results derived from this study, it is suggested in the future to extend this study to a more detail evaluation by prolonging the duration of the study, as well as conducting questionnaire survey with the users. The comparative analysis between the field measurement and the questionnaire survey will provide more solid findings in determining the thermal comfort condition inside a heritage mosque.

The findings from this study is also hoped to become motivation to investigate in detail the indoor environment of heritage building. Though it is already known that heritage buildings normally have good respond to the local climate and environment, the detail investigation using measurement tools will enhance the understanding of the actual condition. With deep understanding, it will help the effective implementation of heritage building characteristics at modern buildings.

\section{Acknowledgements}

The authors would like to express great gratitude to Ministry of Education Malaysia and Universiti Kebangsaan Malaysia for funding this study through research grant FRGS/1/2015/SSI11/UKM/02/2 and GGP-2017-046, respectively. The authors would also like to thank Center of Excellence for Engineering and Technology (CREATE), Public Works Department of Malaysia.

\section{References}

1. Thompson D 1996 The Concise Oxford Dictionary of Current English Fifth ed. (London: BCA) p 634

2. Wilkinson S, Remøy H 2017 Heritage building preservation vs sustainability? Conflict isn't inevitable [cited 2018 Jul 25]. Available from: http://theconversation.com/heritage-building-preservation-vs-sustainability-conflictisnt-inevitable-83973

3. Law of Malaysia 2006 National Heritage Act 2005 Percetakan Nasional Malaysia Bhd.

4. Darmawan E and Enis A S 2016 The changing function of heritage building for roling tourism planning progress Proceedia-Social Behav Sci 227 712-9

5. Ja'afar N H, Sulaiman A B and Shamsuddin S 2012 Traditional street activities in Kuala Lumpur city centre Int J Multidiscip Thoughts 2 93-105

6. Shamsuddin S and Ujang N 2008 Making places: The role of attachment in creating the sense of place for traditional streets in Malaysia Habitat Int. 32 399-409 
7. MIsIrlIsoy D and Günçe K 2016 Adaptive reuse strategies for heritage buildings: A holistic approach. Sustain Cities Soc. 26 91-8

8. Fabbri K, Zuppiroli M and Ambrogio K 2012 Heritage buildings and energy performance: Mapping with GIS tools. Energy Build 48 137-45

9. Llorens J and Zanelli A 2016 Structural Membranes for Refurbishment of the Architectural Heritage. In: Procedia Engineering 15518 - 27

10. Martinez-Molina A, Boarin P, Tort-Ausina I and Vivancos J L 2018 Assessing visitors' thermal comfort in historic museum buildings: Results from a Post-Occupancy Evaluation on a case study Build Environ. 132 291-302

11. Djamila H 2017 Indoor thermal comfort predictions: Selected issues and trends Renew Sustain Energy Rev 74 569-80

12. Carlucci S, Bai L, de Dear R and Yang L 2018 Review of adaptive thermal comfort models in built environmental regulatory documents Build Environ 137 73-89

13. Caetano D S, Kalz D E, Lomardo L L B and Rosa L P 2017 Evaluation of thermal comfort and occupant satisfaction in office buildings in hot and humid climate regions by means of field surveys Energy Procedia 115 183-94

14. Yusoff W F M 2017 Thermal comfort at Semi Open Plaza in Commercial Building: The Case Study of Bangi Gateway Shopping Complex. In: Putrajaya International Built Environment, Technology and Engineering Conference (PIBEC3) Putrajaya $\mathrm{p}$ 30-8

15. He Y, Liu M, Kvan T and Peng S 2017 An enthalpy-based energy savings estimation method targeting thermal comfort level in naturally ventilated buildings in hot-humid summer zones Appl Energy 187 717-31

16. Humphreys M A, Rijal H B and Nicol J F 2013 Updating the adaptive relation between climate and comfort indoors; new insights and an extended database Build Environ $\mathbf{6 3}$ $40-55$ 